neurons become cholinergic when placed in tissue culture ${ }^{1,7}$. But this adrenergicto-cholinergic switch is triggered by conditioned medium most easily in neurons from neonates and occurs earlier rather than later during the culturing process $^{7-9}$. The adult coeliac neurons

\footnotetext{
1. McLachlan, E. M. \& Keast, J. R. Nature 361, 310 (1993).

2. Benham, C. D. Nature 359, 103-104 (1992)

3. Burnstock, G. Neurochem. int/ 2, 357-368 (1990).

4. Evans, R. J. \& Surprenant, A. Br. J. Pharmac. 106, 242-249 (1992)

5. Evans, R. J., Derkach, V. \& Surprenant, A. Nature 357 503-505 (1992)

6. Edwards, F. A., Gibb, A. J. \& Colquhoun, D. Nature 359 , 144-147 (1992)

. Furshpan, E. J. et al. Proc. natn. Acad. Sci. U.S.A. 73. 4225-4229 (1976).

8. Johnson, M. I. et al. J. Cell Biol. 84, 680-691 (1980)

9. Potter, D. D. et al. J. Neurosci. 6, 1080-1098 (1986)

10. Vanner, S. et al. J. Neurophysiol, (in the press).

11. Coggan, J. S., Gruener, R. \& Kreulen, D. L. J. auton. nerv. Sys. 34, 147-156 (1991)
}

we $\mathrm{e}^{5,10}$ and others ${ }^{11}$ have studied are not provided with conditioned medium and maintain their catecholaminergic phenotype for more than 2 months in culture. Nicotinic synaptic transmission therefore is not to be expected and has not been observed; only ATP fast synaptic potentials have been recorded during this time. McLachlan and Keast appear to disdain these purinergic synapses as an artefact of culture; we view such synaptic purity as a virtue rather than a vice for studying mechanisms of action of this 'new' fast neurotransmitter.

\section{Annmarle Surprenant}

Richard J. Evans

Vollum Institute,

Oregon Health Sciences University,

Portland

Oregon 97201, USA

\title{
HIV vaccination dilemma
}

SIR - Ada et al. in their Commentary ${ }^{1}$ discussed my paper $^{2}$ on the improbability of effective vaccination against human immunodeficiency virus (HIV) because of its intracellular transmission and rectal (or vaginal cervical) port of entry.

Neither antibodies nor cell-mediated immunity (CMI) is effective against intracellular transmission of HIV infection - CMI is directed against the viral antigens expressed on some HIVinfected cells but not on others in which HIV is suppressed as complementary DNA of HIV integrated in chromosomes. Ada et al. pointed out that such cells are, as a rule, foreign (allogeneic) to the recipient. Accordingly, they assumed that such allogeneic HIVinfected lymphocytes in the semen (or blood) would be rapidly destroyed by the recipient host cells, and that "if the HIV cDNA in live or dead semen cells were to be transferred undamaged in some novel way to the live host cells, as Sabin suggests, expression of viral peptides could also occur. If so, the 'transfected' host cells would be recognized by cytotoxic $\mathrm{T}$ lymphocytes (CTLs) in the vaccinated host." They added that "Cells in the donated semen already expressing viral antigen could fuse with host cells (gp120/CD4 interaction), and thus be recognized by both class I MHC restricted CTLs resulting from the vaccination and alloreactive CTLs."

The 'flaw' in this argument is that there is a "novel way" by which HIVinfected lymphocytes have been demonstrated to be capable of rapidly transferring infectious virus, either HIV RNA or chromosomally integrated HIV cDNA (without expressed viral antigens or peptides combined with class I MHC), in HIV-infected cells by cell-to-cell contact without using CD4 receptors. This phe- nomenon was recently described by Phillips and Bourinbaiar ${ }^{3}$, who showed that "contrary to infection with free virus, the cell to cell infection was not blocked by anti-gp120 or antiviral serum from HIVpositive individuals". These authors concluded that these "observations offer an insight into the cellular sequence of events which may take place during sexual transmission of HIV across an intact epithelial barrier." Even before HIV was identified as the cause of AIDS, Shearer ${ }^{4}$ suggested "allogeneic leukocytes as possible factors in induction of AIDS in homosexual men". Ada et al., in downplaying "the efficacy of transmission of HIV infection by sexual intercourse, including receptive anal intercourse, and needle sharing" disregard the fact that in the United States in 1991, $64 \%$ of the reported cases of AIDS occurred in homosexuals, $6 \%$ in heterosexuals, and $23 \%$ among people involved only in intravenous drug abuse. The reported rapid transfer of HIV in its various intracellular states by cell-to-cell contact $^{3}$, before the allogeneic mechanism can come into play, is the "novel way".

Also of relevance is the report ${ }^{5}$ that purified proviral DNA of simian immunodeficiency virus (SIV) is infectious in vivo but not in vitro. Ada et al., in pointing to the effectiveness of some vaccines against intravenous challenge by cell-free virus, also overlook a report ${ }^{6}$ showing that vaccinated monkeys protected against an intravenous challenge with 25 monkey-infectious doses of cellfree SIV were not protected against a similar dose of intracellular SIV.

It is evident from the natural history of HIV infection in human beings that the antibody and cell-mediated immune responses are inadequate in preventing the accumulation in the lymph nodes and other tissues of a reservoir of HIVinfected cells (many with only chromosomally integrated suppressed cDNA), which remain dormant for many years until they are activated (derepressed) by as yet incompletely understood events. Moreover, there is increasing recognition of mechanisms by which host immune defences are counteracted to produce latent and persistent infections by viruses $^{7}$.

The continuing failure to use infected cells by various routes, rather than only cell-free virus by the intravenous route, to test for protection produced by vaccination was again evident in a report ${ }^{8}$ on the protective effect of a live attenuated SIV vaccine, with a deletion of the nef gene, in which two of four rhesus monkeys which previously resisted an intravenous challenge with ten cellfree monkey-infectious doses of virus, resisted a subsequent intravenous challenge with 1,000 cell-free monkeyinfectious doses. The enthusiastic response of HIV vaccinologists to this finding ${ }^{9}$ shows the widespread naivety about what live virus vaccines cannot be expected to achieve. I said ${ }^{2}$ that: "A live genetically engineered safe deletion mutant of HIV or SIV cannot be expected to do more than [natural infection with] the unmodified virus", which may perhaps be called Sabin's law about live virus vaccines.

There is no scientific evidence that any of the experimental vaccines against SIV or HIV, some of which are scheduled for use in large-scale human trials, have any protective effect against natural modes of transmission in previously uninfected or latently infected hosts. Ada et al. said that "to delay or not perform such trials for the reason proposed by Dr Sabin would be disastrous for the increasing numbers of people exposed to the risk of infection". In my judgement, it would be disastrous to continue the current inadequate methods of study of HIV and SIV vaccines, and to carry out largescale tests in humans of vaccines without adequate evidence that such vaccines can protect against natural infection with adequate doses of intracellular virus.

Albert B. Sabin*

Washington DC 20016, USA

\footnotetext{
1. Ada, G., Blanden, B. \& Mullbacher, A. Nature 359, 572 (1992).

2. Sabin, A. B. Proc. natn. Acad. Sci. U.S.A. 89, 8852 8855 (1992)

3. Phillips, D. M. \& Bourinbaiar, A. S. Virology 186. 261-273 (1992)

4. Shearer, G. M. N. Engl. J. Med. 308, 223-224 (1983)

5. Letvin, N. L. et al. Nature 349, 573 (1991)

6. Johnson, P. R. et al. in Vaccines 92: Modern Approaches to New Vaccines including Prevention of AIDS (eds Brown, F. et al. 95-102 (Cold Spring Harbor, 1992). 7. Gooding, L. R. Cell 71, 5-7 (1992).

8. Daniel, M. D. et al. Science 258, 1938-1941 (1992)
}

9. Cohen, J. Science 258, 1880-1881 (1992).

* Dr Sabin died on 3 March. Nature will be printing an obituary shortly. 